\title{
The fate of small-size pericardial heart valve prostheses in an older patient population
}

\author{
Ruggero De Paulis, MD, ${ }^{\mathrm{a}}$ Salvatore D'Aleo, MD, ${ }^{\mathrm{a}}$ Alessandro Bellisario, MD, ${ }^{\mathrm{a}}$ Andrea Salica, MD, ${ }^{\mathrm{a}}$ \\ Luca P. Weltert, MD, ${ }^{a}$ Raffaele Scaffa, MD, ${ }^{a}$ Lorenzo Guerrieri Wolf, MD, ${ }^{a}$ Daniele Maselli, MD, ${ }^{a}$ and \\ Michele Di Mauro, MD $^{b}$
}

\begin{abstract}
Background: Structural valve deterioration (SVD) is the Achilles' heel of bioprostheses. Its correlation with younger age is well known. In recent years we exclusively reserved use of small-size Mitroflow valve prostheses (LivaNova, London, United Kingdom) to an older patient population with small aortic annuli. This study aimed to assess the incidence of SVD and its effect on patient survival and need for reoperation.
\end{abstract}

Materials and Methods: Two hundred five patients (aged $75.9 \pm 5.3$ years; range, 62-92 years) underwent aortic valve replacement with a $19-\mathrm{mm}$ or 21-mm Mitroflow valve prosthesis between 2005 and 2011. The great majority was female $(\mathrm{n}=170 ; 83 \%)$. In half of patients it was an isolated procedure. All valve prostheses were implanted in a supra-annular position using pledgeted sutures. A $19-\mathrm{mm}$ valve was implanted in 93 patients $(45.3 \%)$, whereas in 112 patients $(54.6 \%)$ a $21-\mathrm{mm}$ valve was used.

Results: Twenty-three patients $(11.2 \%)$ were diagnosed with early SVD by echocardiography. Average time from surgery to diagnosis of SVD was $64.3 \pm 26.8$ months. Ten patients needed a reoperation for SVD. Average time from surgery to a second operation was $45.7 \pm 35.7$ months. Overall survival was $64.5 \%$ and $42.3 \%$ at 5 and 9 years, respectively. Cumulative freedom from SVD at 5 and 9 years was $94.8 \% \pm 1.6 \%$ and $77.4 \% \pm 5.4 \%$, respectively. In 4 patients death was linked to the presence of SVD. There were no differences in mortality, reoperation, or SVD between the 2 Mitroflow valve sizes.

Conclusions: Small-size Mitroflow pericardial valve prostheses have shown a worrisome incidence of SVD even in patients aged $>70$ years. Based on this experience we have discontinued their use. (J Thorac Cardiovasc Surg 2017;153:31-9)

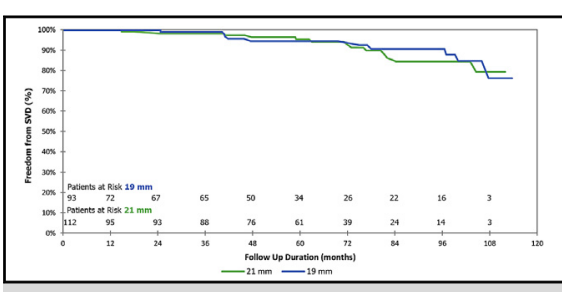

Freedom from structural valve deterioration in 19and 21-mm Mitroflow valve prostheses (LivaNova, London, United Kingdom).

Central Message

Small-size Mitroflow pericardial valve prostheses (LivaNova, London, United Kingdom) have shown a worrisome incidence of SVD even in patients aged $>70$ years. Its limited durability should be acknowledged when considering elderly patients.

Perspective

Because of their manufacturing characteristics, small-size Mitroflow valve prostheses (LivaNova, London, United Kingdom) are usually preferred in patients with small aortic annuli whenever avoidance of an annulus enlargement procedure is considered for anatomic or patient-related factors. However, structural valve deterioration might start 5 years after implantation considerably limiting their use, even in an older patient population.

See Editorial Commentary page 40
Stented pericardial valve prostheses are used with increased frequency because of the aging of the population and the tendency to avoid anticoagulation with its related morbidity and mortality. Because of the need for the stent and the sewing ring, all valve prostheses cause a certain degree of obstruction in the left ventricular outflow tract and are often responsible for a certain degree of patient-prosthesis mismatch (PPM). ${ }^{1}$ An annulus enlargement procedure is sometimes necessary to fit larger prostheses and avoid high postoperative transprosthetic gradients. ${ }^{2}$ Stentless

\footnotetext{
From the ${ }^{\mathrm{a} C a r d i a c}$ Surgery Department, European Hospital, Rome; and ${ }^{\mathrm{b}}$ Cardiac Surgery Unit, University of Chieti, Chieti, Italy.

Received for publication Nov 2, 2015; revisions received Aug 26, 2016; accepted for publication Aug 30, 2016; available ahead of print Oct 21, 2016.

Address for reprints: Ruggero De Paulis, MD, Cardiac Surgery Department, European Hospital, Via Portuense 700, 00149 Roma, Italy (E-mail: depauli@tin.it). $0022-5223 / \$ 36.00$

Copyright (c) 2016 by The American Association for Thoracic Surgery http://dx.doi.org/10.1016/j.jtcvs.2016.08.063
}

Scanning this QR code will take you to supplemental figure and table for this article. 


\section{Abbreviations and Acronyms \\ $\mathrm{EF}=$ ejection fraction \\ SVD $=$ structural valve deterioration \\ PPM $=$ patient-prosthesis mismatch}

valves can also be used to decrease the intrinsic obstruction of an aortic prosthesis. ${ }^{3}$

The Mitroflow aortic valve prosthesis (LivaNova, London, United Kingdom) was specifically designed to reduce flow obstruction by minimizing the size and thickness of the sewing ring and by placing the pericardial leaflet on the outside of the stent post to maximize the valve opening area. ${ }^{4}$ Because of its intrinsic manufacturing characteristics, a Mitroflow valve prosthesis can be easily implanted where other pericardial valves of corresponding size might not fit or would require an annulus enlargement. ${ }^{5}$ The implant technique does not differ from that used for any kind of standard stented prosthesis.

During the past 10 years we have used the Mitroflow aortic valve bioprostheses, 19- and 21-mm sizes, with the specific intention to avoid annulus enlargement in older and high-risk patients with small aortic annuli.

For this report we analyzed the medium-term results of this peculiar patient population by assessing patient survival, incidence of structural valve deterioration (SVD) by echocardiography, and need for reoperation.

\section{MATERIALS AND METHODS}

From March 2005 until December 2011, 205 consecutive 19-mm and 21-mm Mitroflow aortic valves were implanted by the Cardiac Surgery Department of the European Hospital in Rome, Italy. The great majority of patients was aged $>70$ years (mean age, $75.9 \pm 5.3$ years; range, 62-92 years; median, 76 years) and the great majority was female $(\mathrm{n}=170 ; 83 \%)$.

During the same period, a total of 803 Perimount and Magna Ease aortic valve prostheses (Edwards Lifesciences, Irvine, Calif) were implanted. Four hundred thirty of them were either a 19- or 21-mm valve. Overall, the use of the Mitroflow valve represents $20.3 \%$ of all patient cohorts and $32.3 \%$ of all 19- and 21-mm valve prostheses implanted during the period.

All valve prostheses were implanted using the same technique: Supra-annular placement with the use of 2-0 pledgeted sutures through a median sternotomy. Antegrade blood cardioplegia was always used. Valve prostheses were prepared according to the instruction manual with a series of 2-minute rinses in physiologic saline solution.

During the postoperative course all patients were discharged on antiplatelet therapy only. Anticoagulation was started only in the presence of chronic or parossistic atrial fibrillation.

Postoperative echocardiography was conducted before each patient's discharge.

All patients undergoing operation had clinical and echocardiographic assessment during 2 months of follow-up (November and December 2014). For patients unable or unwilling to travel, clinical and echocardiographic data were obtained from the referring cardiologist. For those patients undergoing reoperation the last available echocardiography was considered. Among the entire population, around two-thirds of patients had echocardiography follow-up at regular intervals.

\section{Study Design and Definitions}

In-hospital and follow-up data were retrospectively analyzed. The study was carried out in accordance with The American Association for Thoracic Surgery/Society for Thoracic Surgeons/European Association for Cardio-Thoracic Surgery Guidelines for reporting valve morbidity and mortality. ${ }^{6}$ Patient symptoms were carefully evaluated. SVD was defined as manifest progression of mean aortic transprosthetic gradient $\geq 35 \mathrm{~mm}$ $\mathrm{Hg}$ paralleled by a decreased effective orifice area or by autoptical evidence. Severe PPM was defined as an effective orifice index area of the aortic prosthesis $\leq 0.65 \mathrm{~cm}^{2} / \mathrm{m}^{2}$.

Considered end points were overall mortality, valve-related mortality, cardiac mortality (including valve-related), SVD, and reoperation for SVD.

\section{Statistical Analysis}

All data processing was carried out independently by a statistician not involved in the data collection process on a workstation running IBMSPSS version 20.0 (IMB-SPSS Inc, Armonk, NY), R version 3.2.5 (R Foundation for Statistical Computing, Vienna, Austria), MEDCalc version 16 (Ostend, Belgium), and Windows 10 (Microsoft, Redmond, Wash).

Data are reported as mean \pm standard deviation for continuous variables and as absolute number/relative incidence for categorical variables.

Preoperative variables were acquired from the original clinical files and they were complete for all patients; follow-up was 100\% complete.

Mortality and morbidity are presented as actuarial incidences; Kaplan-Meier method and $\log$ rank test were used to analyze time-related events nonsusceptible to competing risk (overall mortality and valve-related mortality). Cumulative incidence was used to assess late events (aortic valve replacement for SVD and SVD) susceptible to competing risk bias. Comparison between curves was performed by Gray test. Survival curves include in-hospital deaths.

A box plot with pairwise comparison $P$ values $(P<.05$ vs discharge) was used to display results of repeated echocardiography (Figure 1). In the graph are indicated the absolute number of patients, the percentage of overall population, and the remaining patients at risk for each time frame.

The following preoperative variables that could correlate with death or SVD were considered: sex, age, body surface area, body mass index, ejection fraction (EF), dyslipidemia, diabetes, hypertension, chronic renal failure, chronic obstructive pulmonary disease, associated procedure, valve size, and presence of PPM.

Either Cox regression model or interval censored hazard function was used to test correlations between covariates and either mortality and morbidity, according to defined end points; to increase the robustness of the analysis, results were also compared using Tarone-Ware and Breslow models. A $P$ level of .05 was considered significant for univariate analysis and the variable was entered into a multivariate regression model. Full data of the regression analysis is available in Table E1.

\section{RESULTS \\ Demographic and Patient Characteristics}

Complete preoperative patient characteristics are shown in Table 1. The mean age of patients was $75.9 \pm 5.3$ years and the great majority was female $(\mathrm{n}=170 ; 83 \%)$. Mean body surface area was $1.7 \pm 0.1 \mathrm{~m}^{2}$. All patients had New York Heart Association functional class higher than II. Indication for surgery was aortic valve stenosis in $84.8 \%$ (174 patients); the remaining $15.2 \%$ (31 patients) had mixed lesions. Mean aortic transvalvular gradient at time of operation was $50.5 \pm 15.9 \mathrm{~mm} \mathrm{Hg}$. Hypertension was present in $71 \%(\mathrm{n}=147)$, dyslipidemia in $36.1 \%$ $(\mathrm{n}=74)$, and diabetes was seen in $24.4 \%(\mathrm{n}=50)$ of the population. 


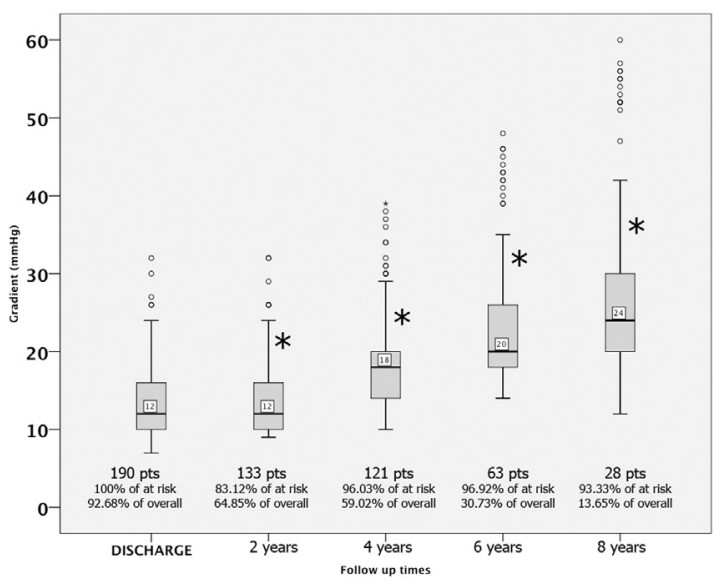

FIGURE 1. Mean transprosthetic gradient average values and outliers in longitudinal echocardiography surveillance. ${ }^{*} P<.05$ versus discharge.

The great majority of patients underwent elective operation. In about half of cases it was an isolated aortic valve replacement, although it was associated with other surgical procedures in the other half of cases. All patients received a 19- or 21-mm Mitroflow bioprostheses (12A model in 39 patients and LXA model in 166 patients). The 19 -mm valve was implanted in 93 patients $(45.3 \%)$, whereas in 112 patients $(54.6 \%)$ a $21-\mathrm{mm}$ valve was used (Table 2).

Cardiopulmonary bypass and aortic crossclamping times were $84 \pm 31$ minutes and $64 \pm 27.5$ minutes, respectively.

The proportion of postoperative renal failure was $18 \%$ $(\mathrm{n}=37)$. Revision for bleeding was necessary in $4.4 \%$

TABLE 1. Baseline characteristics of the population $(N=205)$

\begin{tabular}{lc}
\multicolumn{1}{c}{ Characteristic } & Result \\
\hline Clinical data & \\
Female & $170(82.9)$ \\
Age, y & $75.9 \pm 5.3$ \\
Body surface area, ${ }^{2}$ & $1.7 \pm 0.1$ \\
$\quad$ Body mass index & $26.4 \pm 4$ \\
$\quad$ Atrial fibrillation & $33(16.1)$ \\
High blood pressure & $147(71.7)$ \\
Diabetes mellitus & $50(24.4)$ \\
Dyslipidemia & $74(36.1)$ \\
Tobacco use history & $35(17.1)$ \\
Comorbidities & \\
Chronic obstructive pulmonary disease & $26(12.7)$ \\
Preoperative renal failure & $27(13.2)$ \\
Myocardial infarction history & $23(11.2)$ \\
Coronary angioplasty & $11(5.4)$ \\
Echocardiographic data & \\
LVEF, \% & $54.5 \pm 9.3$ \\
LVEF $<$ 50\% & $41(20.0)$ \\
Mean aortic gradient, mm Hg & $50.7 \pm 15.9$ \\
Aortic stenosis & $174(84.8)$ \\
Mixed lesions & $31(15.2)$ \\
\hline Values are presented as n (\%) or mean \pm standard deviation. LVEF, Left ventricular \\
ejection fraction.
\end{tabular}

TABLE 2. Intraoperative data of the population $(N=205)$

\begin{tabular}{lc}
\hline Isolated AVR & $97(48.3)$ \\
Concomitant procedures & $108(52.7)$ \\
Coronary artery bypass grafting & $62(30.2)$ \\
Mitral valve replacement & $32(15.6)$ \\
Mitral valve repair & $8(3.9)$ \\
Tricuspid annuloplasty & $17(8.3)$ \\
Mitral valve and tricuspid valve surgery & $57(27.8)$ \\
Ascending aorta replacement & $9(4.4)$ \\
Others & $16(7.8)$ \\
Valve size, mm & \\
19 & $93(45.3)$ \\
21 & $112(54.6)$ \\
Bioprosthesis model* & \\
12A & $39(19)$ \\
LXA & $166(81)$ \\
Surgical data & \\
Elective surgery & $204(99.5)$ \\
Urgent or emergency surgery & $1(0.5)$ \\
Redo & $2(1)$ \\
\hline
\end{tabular}

Values are presented as $\mathrm{n}(\%) . A V R$, Aortic valve replacement. *Mitroflow (LivaNova, London, United Kingdom)

$(\mathrm{n}=9)$. Postoperative atrial fibrillation occurred in $27 \%$ $(\mathrm{n}=55)$ of the patients. Finally, 8 patients $(3.9 \%)$ required a pacemaker for postoperative atrioventricular block.

Mean posthospital discharge follow-up time was $60.8 \pm 29$ months; median posthospital discharge followup time was 60.9 months $(95 \%$ confidence interval [CI], 55-65 months) ranging from 3 to 113 months. None of these patients was lost at follow-up.

\section{Overall Survival}

A total of 91 patients were dead at the time of follow-up. Overall survival was $82.3 \%, 64.5 \%, 46.4 \%$, and $42.3 \%$ at $1,5,8$, and 9 years, respectively. At 5 years patients at risk represented $46.3 \%(\mathrm{n}=95)$ of the whole population, whereas at 8 years they made up $15 \%(\mathrm{n}=31)$. No significant difference in terms of mortality was seen between the 2 groups of Mitroflow valve sizes (Figure 2). Cox analysis revealed age (hazard ratio [HR], 1.087; 95\% CI, 1.045-1.126; $P<.001$ ), preoperative EF (HR, 0.969; $95 \% \mathrm{CI}, 0.948-0.985 ; P=.004)$, and associated procedure (HR, $1.569 ; 95 \%$ CI, $1.025-2.403 ; P=.038$ ) as significantly correlated with death.

\section{Early Mortality}

No intraoperative death occurred. Fifteen patients $(7.3 \%)$ died within the first 30 days after surgery. Three deaths $(1.5 \%)$ were potentially valve-related (in 2 cases caused by mesenteric ischemia and 1 due to cerebral hemorrhage). Three patients (1.5\%) died from cardiogenic shock and the remaining 9 deaths $(4.4 \%)$ were noncardiacrelated (respiratory failure in 4 cases, and multiorgan failure in 5 cases). 


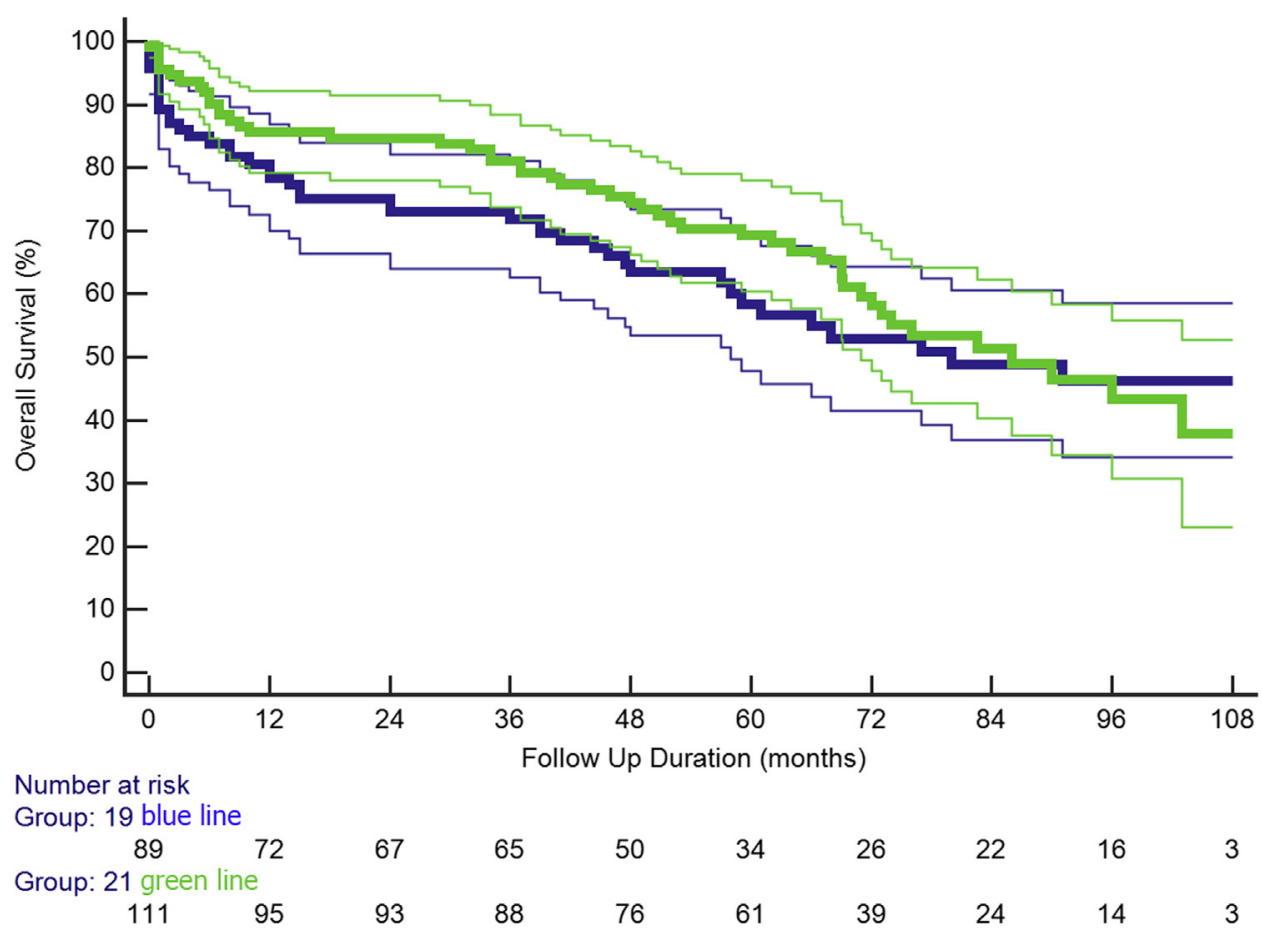

FIGURE 2. Overall survival and patients at risk in the whole patient population divided by size 19- or 21-mm Mitroflow valve prostheses (LivaNova, London, United Kingdom).

\section{Late Mortality}

Seventy-six patients $(36.6 \%)$ died during follow-up. Thirty-five deaths were noncardiac-related. In 10 cases the cause of death was unknown or undetermined. Thirty-one deaths were due to cardiac-related events.

\section{TABLE 3. Long-term causes of death}

\begin{tabular}{lc}
\hline \multicolumn{1}{c}{ Cause of death } & Result \\
\hline Long-term deaths & $76(37.1)$ \\
Valve-related & $23(11.2)$ \\
Sudden death & 8 \\
Stroke & 5 \\
Cerebral bleeding & 2 \\
Endocarditis & 4 \\
Congestive heart failure for SVD & 2 \\
Cardiogenic shock after re-AVR & 1 \\
Sepsis after re-AVR & 1 \\
Cardiac-related & $8(3.9)$ \\
Congestive heart failure & 7 \\
Myocardial infarction & 1 \\
Not cardiac-related & $35(17.1)$ \\
Cancer & 12 \\
Renal failure & 9 \\
Respiratory failure & 10 \\
Traumatic event & 3 \\
Epatic failure & 1 \\
Unknown & $10(4.9)$ \\
\hline
\end{tabular}

Values are presented as $\mathrm{n}$ or $\mathrm{n}(\%)$. SVD, Structural valve deterioration; $A V R$, aortic valve replacement.
In 23 cases the death was considered valve-related (Table 3).

Cox analysis revealed age (HR, 1.077; 95\% CI, $1.009-1.151 ; P=.026)$ and female sex (HR, 2.581; 95\% CI, 1.135-5.872; $P=.024)$ as significant factors correlating with valve-related long-term mortality.

Valve-related mortality as reported in Figure 3 was $79.5 \% \pm 4.1 \%$ at 9 years.

\section{SVD}

The mean postoperative transvalvular gradient at discharge was $12.5 \pm 5.3 \mathrm{~mm} \mathrm{Hg}$ and none of the patients displayed evidence of periprosthetic leak. The mean EF at discharge was $53.3 \% \pm 9.1 \%$. Echocardiographic parameters at discharge according to prosthesis size are displayed in Table 4. Analysis of variance for repeated measures under sphericity assumption revealed a highly significant $(P=.0001)$ progression of mean gradient up to $23.9 \pm 7.2 \mathrm{~mm} \mathrm{Hg}$ (the peak transprosthetic gradient was $40.3 \pm 11.3 \mathrm{~mm} \mathrm{Hg}$ ). The mean $\mathrm{EF}$ at last follow-up was $54.9 \% \pm 7.2 \%$. A box plot with pairwise comparison $P$ values $(P<.05$ vs discharge) displays results of repeated echocardiography (Figure 1).

Twenty-three patients showed clinical signs of increased transvalvular gradient. Two patients died because of congestive heart failure due to the presence 


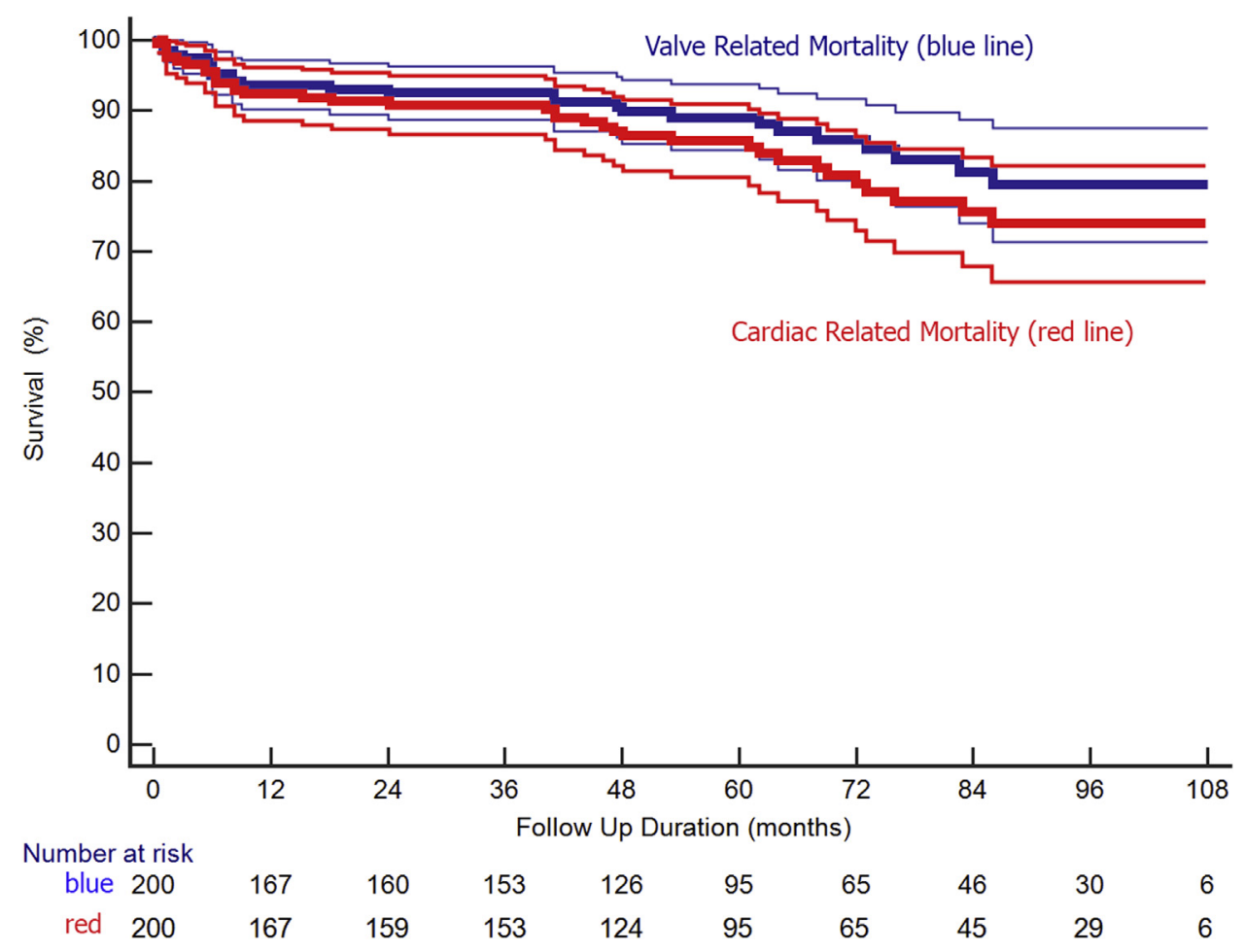

FIGURE 3. Cardiac- and valve-related mortality and patients at risk, for the operative survivors.

of significant SVD; 11 patients showed a mean transprosthetic gradient $>35 \mathrm{~mm} \mathrm{Hg}$ and are being monitored closely. The remaining 10 patients were symptomatic and had a mean gradient well above $50 \mathrm{~mm} \mathrm{Hg}$ and needed reoperation. Four of these patients had received the $19-\mathrm{mm}$ valve and 6 patients had received the 21$\mathrm{mm}$ valve. Mean time from first surgery to reoperation was $45.7 \pm 35.7$ months (range, 15-105 months). Two of these 10 patients underwent a transcatheter aortic valve implantation procedure and in the remaining 8 patients the Mitroflow bioprosthesis was explanted. The explanted valve invariably appeared more rigid and stiff than calcified, with marked signs of fusion at the commissural level and severe reduction of leaflets mobility. Of this subgroup, 5 patients received a Regent mechanical valve $(17 \mathrm{~mm}$ size; St Jude Medical, St Paul, Minn) and 3 patients had implanted an 18-mm Overline mechanical prosthesis (LivaNova, London, United Kingdom). Two of these reoperations were carried out in a different cardiac surgery unit. Freedom from reoperation because of SVD was $97.5 \% \pm 1.1 \%$ and $93.7 \% \pm 2.1 \%$ at 5 and 8 years, respectively (Figure 4).

Average time to SVD as diagnosed by a mean gradient $>35 \mathrm{~mm} \mathrm{Hg}$ was $64.3 \pm 26.8$ months (range, 15-108 months).

Cumulative freedom from SVD at 5 and 8 years was $94.8 \% \pm 1.6 \%$ and $87.2 \% \pm 2.8 \%$, respectively (Figure 5). Figure 6 reports the cumulative freedom from SVD when divided for the 2 sizes of the Mitroflow prosthesis. No significant differences were evident (Gray test $P=.235$ ); at 8 years freedom for SVD was $90.6 \% \pm 3.5 \%$ for the $19-\mathrm{mm}$ valve and $84.4 \% \pm 4.2 \%$ for the 21-mm valve.

Based on interval censored hazard analysis, only older age was significantly correlated to decreased incidence of SVD (HR, 0.8934; 95\% CI, 0.8163-0.9831; $P=.030)$.

TABLE 4. Echocardiographic parameters at discharge according to prosthesis size

\begin{tabular}{|c|c|c|c|c|}
\hline Valve size, $\mathbf{m m}^{*}$ & n $(\%)$ & $\begin{array}{c}\text { Ejection fraction } \\
(\% \pm \text { standard deviation })\end{array}$ & Mean gradient $(\mathrm{mm} \mathrm{Hg} \pm$ standard deviation) & Prosthesis-patient mismatch $(\mathrm{n}[\%])$ \\
\hline 19 & $93(45.3)$ & $55.3 \pm 8.1$ & $13.2 \pm 5.4$ & $10(10.7)$ \\
\hline 21 & $112(54.6)$ & $51.7 \pm 9.5$ & $12.1 \pm 5.1$ & $0(0)$ \\
\hline
\end{tabular}




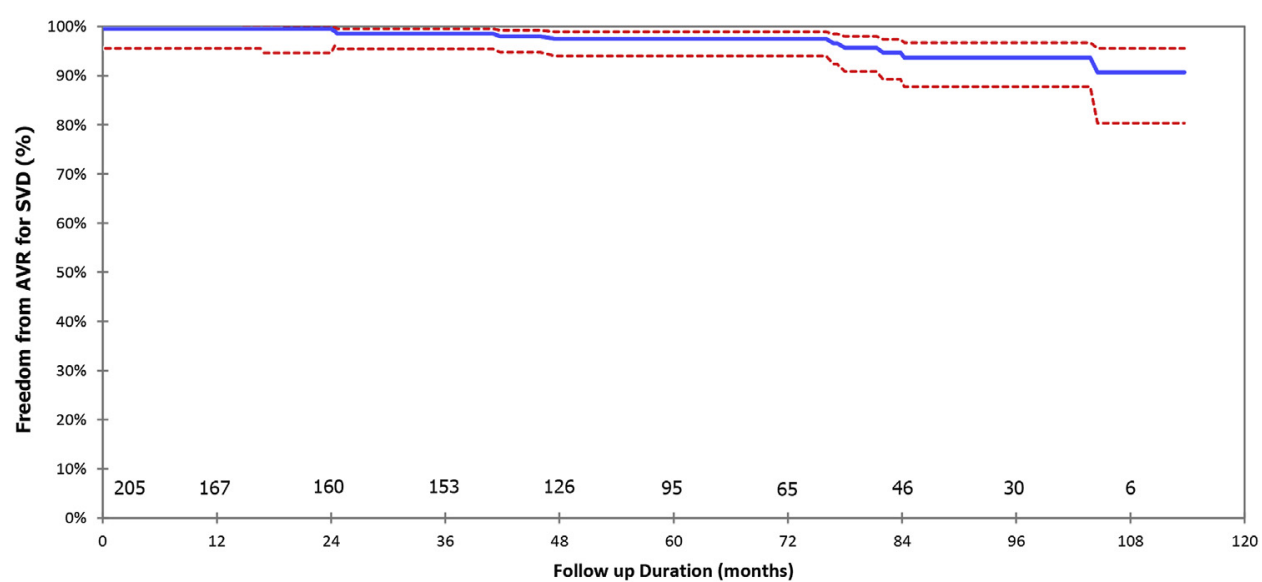

FIGURE 4. Freedom from reoperation because of structural valve deterioration $(S V D)$ and patients at risk, for the operative survivors. AVR, Aortic valve replacement.

An age-related nomogram for SVD was plotted, based on the values extrapolated from interval censored hazard analysis (Figure E1). However, given the small number of patients in each age group, any kind of inferential data should be taken with extreme caution.

\section{DISCUSSION}

The Mitroflow pericardial valve, available since 1982, was designed to improve bioprosthesis hemodynamic parameters and its design demonstrated excellent performance, particularly in small aortic annuli. ${ }^{7}$ Due to its design characteristics, superiority with respect to other pericardial valves has been shown, as reported by the Canadian Mitroflow Bioprosthesis Study. ${ }^{8}$

The first Mitroflow model (model 11A) demonstrated SVD due to pericardial cusp tears during early followup. ${ }^{9}$ For this reason the bioprosthesis was redesigned in 1991, with model 12A characterized by less bulk and a better hemodynamic parameters profile. Nowadays, the Mitroflow valve is in its third generation with the LX model that did not substantially modify the design and the performance of the previous valve and could be considered substantially the same bioprosthesis. Despite poor results in terms of early SVD, which was seen with the first model of the Mitroflow aortic valve (ie, model 11A), the second- and third-generation Mitroflow (ie, 12A and LX models) report a comparable follow-up with other bioprostheses commonly available on the market. ${ }^{10-12}$ However, data in terms of SVD remain controversial. Age at implantation is a well-known factor leading to earlier prosthetic deterioration and has been show in $\mathrm{Mi}-$ troflow valves as in other bioprosthesis. ${ }^{13}$ However, our patient population was rather old, with a mean age of 76 years. In one-quarter of patients $(n=49 ; 23.7 \%)$ the patients were octogenarians. Because of the good hemodynamic characteristics of the Mitroflow valve associated with a small sewing ring, we thought to use the valve only in very old patients with a small annulus where the presence of PPM is of less concern and avoidance of annulus enlargement might be advantageous for their frailty. It turned out that the majority of these patients were women, often with a short stature, an average body surface area of $1.7 \mathrm{~m}^{2}$, a rather low incidence of PPM $(10 \%$ only in the $19-\mathrm{mm}$ valve), and a rather high incidence of hypertension; a quarter of them had diabetes and a third of them had dyslipidemia. All these factors are known to play a negative role in the incidence of SVD. However, to our surprise, our multivariate analysis did not find any of these factors to negatively influence the results. Only older age was found to significantly correlate with a reduced incidence of SVD. However, given the mean age of our patients this finding appears to play a marginal role in the evaluation of the performance of the valve prosthesis.

We were surprised by the $7.3 \%$ mortality at 30 days if compared with our own data with the use of other valve prostheses. Although greatly speculative, this finding might be an indication that we have been selecting a patient subgroup with an intrinsically higher operative risk. Nevertheless, these data are substantially in line with various reports in this age group population. As a matter of fact, other authors reviewing their experience with a large number of Mitroflow prostheses of all sizes in patients with a mean age of 76 years recently reported $10.3 \%$ mortality at 30 days. ${ }^{14}$

More than one-third of our population (76 patients) was dead at the time of last follow-up, accounting for an overall survival of $65.5 \%$ and $42.3 \%$ at 5 and 9 years, respectively. Given the mean age of the study population (75.9 \pm 5.3 years) the results are acceptable and comparable to other, similar studies. ${ }^{12,14}$ However, 23 deaths were considered valve-related and in 4 patients were 


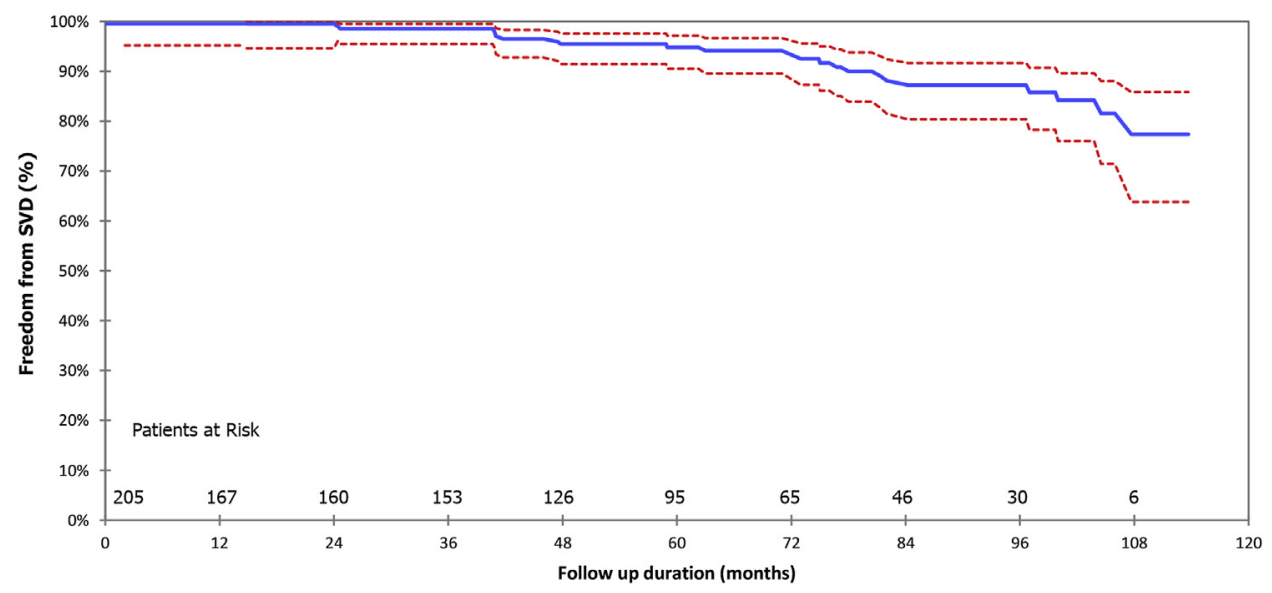

FIGURE 5. Freedom from structural valve deterioration $(S V D)$ (as defined by a mean gradient $>35 \mathrm{~mm} \mathrm{Hg}$ ) and patients at risk, for the operative survivors.

directly linked to SVD: in 2 patients because of congestive heart failure and in 2 patients because of complications after redo surgery. These data might suggest that the use of small Mitroflow valve prostheses even in an older patient population might add an increased risk of premature death.

Despite satisfactory hemodynamic performance as testified to by our immediate postoperative echocardiography findings and as reported by most of reports in the literature, SVD in our study started to be diagnosed about 5 years after surgery. Considering once again the mean age of our population at surgery, most of the patients requiring a reoperation were octogenarians, as are most of the patients being followed-up for an abnormally increased transvalvular gradient. The occurrence of SVD has certainly a substantial influence on a patient's survival. Furthermore, we cannot exclude that some of the unknown, undetermined, or sudden death (not considered SVD) could not be due in part to SVD. For these reasons, given the intrinsic retrospective nature of our study and the age of the population, it is possible that the actual incidence of SVD might be underestimated.

Although current guidelines recommend the use of bioprostheses after age 65 years, we limited the use of small size Mitroflow valves only to patients older than age 70 years. Nevertheless, our 5 years of SVD-free survival was $94.4 \% \pm 2.4 \%$ and $95.3 \% \pm 2.1 \%$ for the $19-$ and $21-\mathrm{mm}$ valve, respectively, but it decreased to $90.6 \% \pm 3.5 \%$ and $84.4 \% \pm 4.2 \%$ at 8 years. This indicates that SVD rate reached $5.2 \%$ within the first 5 years after the operation. These data are slightly better than the $8.4 \%$ incidence of SVD at 5 years recently reported by Senage and colleagues ${ }^{15}$ in a large patient

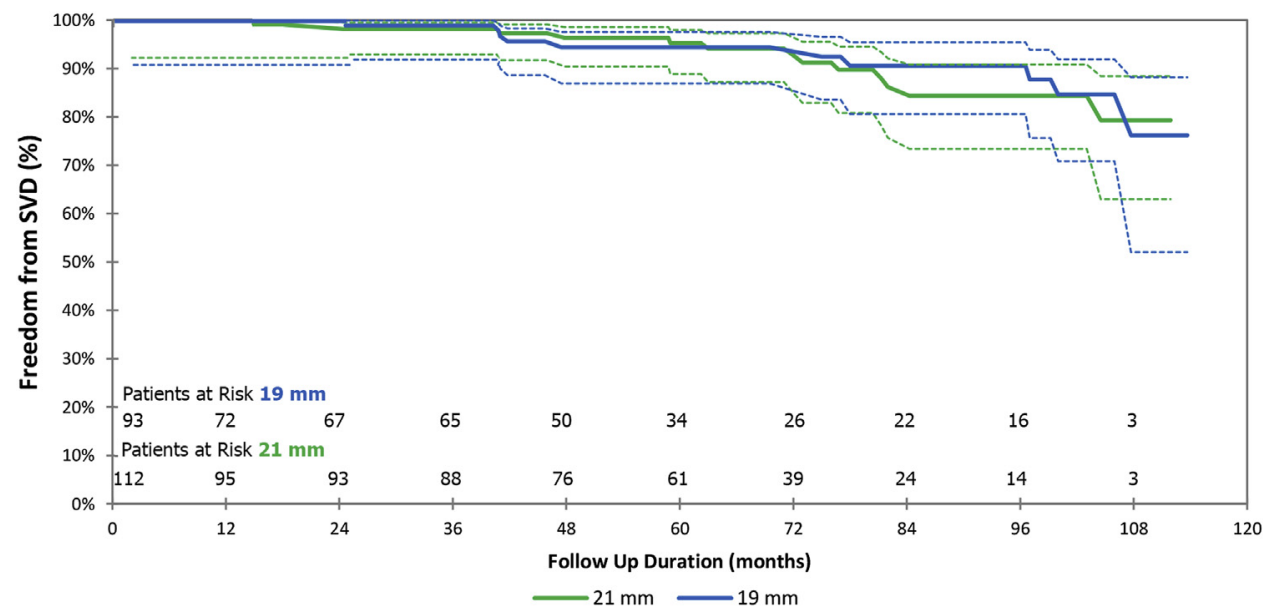

FIGURE 6. Freedom from structural valve deterioration ( $S V D)$ (as defined by a mean gradient $>35 \mathrm{~mm} \mathrm{Hg}$ ) and patients at risk, for the operative survivors, divided by the 2 sizes of implanted Mitroflow valve prostheses (LivaNova, London, United Kingdom). 
cohort. However, at 8 years the incidence of SVD in our cohort climbed to $12.8 \%$. It is possible that considering only patients with small annuli and therefore considering only 19- and 21-mm valves, we selected a patient population at higher risk for SVD. In the cohort of Senage and colleagues, ${ }^{15}$ SVD occurred preferentially in small size bioprostheses with higher postoperative gradient and the presence of PPM. Abnormal mechanics and flow abnormalities related to PPM along with the lack of anticalcification treatment were considered potential causes for an early and accelerated rate of stiffening and calcification. Although the same authors reported that female sex, dyslipidemia, and PPM were risk factors for SVD,${ }^{15}$ we could not find any factors correlating with an increased incidence of SVD. It is possible that the relatively low number of patients with a higher proportion of female patients $(70 \%$ of the total patient population) prevented us from confirming the negative influence on valve durability of some of the known factors. Furthermore, despite the small size of valve used, the incidence of PPM in our population was quite small, with $10 \%$ of severe PPM only for the 19 -mm size. Piccardo and colleagues ${ }^{14}$ also reported an increased incidence of SVD in patients who had received a $19-\mathrm{mm}$ Mitroflow valve prosthesis. In particular, they report freedom from SVD of $64 \%$ at 8 years for $19-\mathrm{mm}$ Mitroflow valve prostheses compared with $88 \%$ for valve sizes $>19 \mathrm{~mm}$. In their series the presence of PPM or a higher gradient at discharge (a surrogate for presence of PPM) was a significant risk factor for early SVD. Given their definition of echocardiographic SVD as a mean gradient $>40 \mathrm{~mm} \mathrm{Hg}$, their 8 years of freedom from SVD in the 19 -mm valve prosthesis was considerably worse than in our patients. However, we also had similar unsatisfactory results in the 21-mm cohort.

Various studies in the literature have found that given the incidence of SVD at 10 years, the Mitroflow valve might be preferable in patients older than age 65 years. ${ }^{16,17}$ In fact, their rate of SVD was $3.13 \%$ per patient-year in the 60 to 69 years age group but it was $1.2 \%$ in the group aged $>70$ years. Minami and colleagues ${ }^{11}$ who also reported, in a large group of patients, a $82.8 \%$ freedom from SVD at 10 years for the whole population, found that it was slightly better only in patients older than age 75 years. Yankah and colleagues $^{12}$ also confirmed a freedom from reoperation for SVD $>80 \%$ at 10 years only in patients aged $>70$ years. Nevertheless, other authors before us have also found an increased rate of SVD even in patients older than age 70 years. In particular, the mean age of their patients was similar to ours (76 years), with an incidence of SVD of $4 \%$ after a median follow-up of 3.4 years; their mean time from first surgery to reoperation was around 6 years. ${ }^{18}$ However, in this specific study the diagnosis was exclusively done at reoperation. As a matter of fact, in most of the published series the diagnosis of SVD was considered only at reoperation and based on the histologic analysis of the explanted valve prostheses. This approach is often the cause of significant underestimation of this type of complication not only because some of the patients who refused or were denied repeat surgery are not considered, but also because all cases of pathologic increased gradient are not considered as pathognomonic of SVD.

In recent years, some of our patients were also included in a multicenter study comprising 1591 patients evaluated over a long-term period. ${ }^{19}$ However, all of our enrolled patients were within the first 3 to 4 years or follow-up when signs of an early SVD were not present. Nevertheless, in this study a consistent proportion of 19- or 21$\mathrm{mm}$ valve prostheses was enrolled and the overall incidence of SVD was satisfactory, especially in patients aged $>70$ years, with a linearized rate of 0.5 per patientyear.

\section{Limitations of the Study}

This study is retrospective, and therefore lacks many of the advantages of prospective evaluation, and although all patients had at least 1 echocardiogram, longitudinal surveillance was not always available, making the reliability of data less than optimal.

Use of Mitroflow valves was intentionally restricted to the 19- and 21-mm valve sizes in our routine practice. They were chosen only when other pericardial valves did not fit the native annulus, or when the presence of severe calcification of the aortic annulus made enlargement procedures challenging, especially in this elderly and frail population. Both of these selection criteria were based on surgeon judgment at the time of surgery.

To avoid the bias related to competing risk when evaluating the freedom from SVD or the freedom from reoperation from SVD, we used competing risk analysis. Because the majority of the studies in the literature used Kaplan-Meier curves to assess similar outcomes, the results might not be directly comparable.

\section{CONCLUSIONS}

Data from the present study show that 19- and 21-mm Mitroflow valves (with no anticalcification treatment) appear to be at risk for an accelerated rate of SVD even in patients aged 70 years or older. They should be used with caution in patients with a life expectancy $>8$ years.

\section{Conflict of Interest Statement}

Authors have nothing to disclose with regard to commercial support. 


\section{References}

1. Rao V, Jamieson E, Ivanov J, Armstrong S, David TE. Prosthesis-patient mismatch affects survival after aortic valve replacement. Circulation. 2000; 102(Suppl III):III-5-9.

2. Peterson MD, Borger MA, Feindel CM, David TE. Aortic annular enlargement during aortic valve replacement: improving results with time. Ann Thorac Surg. 2007;83:2044-9.

3. Ayyaz A, Halstead JC, Cafferty F, Sharples L, Rose F, Coulden R, et al. Are stentless valves superior to modern stented valves? A prospective randomized trial. Circulation. 2006;114(Suppl I):I-535-40.

4. Jamieson WRE, Yankah CA, Lorusso R, Benhameid O, Hayden RI, Forgie R, et al. Clinical and hemodynamic performance of the Sorin Mitroflow pericardial bioprosthesis. In: Chen Y-F, Luo C-Y, eds. Aortic valve. Shanghai: Intech; 2011: 166-74.

5. Jamieson WRE, Koerfer R, Yankah CA, Zittermann A, Hayden RI, Hilton Ling H, et al. Mitroflow aortic pericardial bioprosthesis-clinical performance. Eur J Cardiothorac Surg. 2009;36:818-24.

6. Akins CW, Miller DC, Turina MI, Kouchoukos NT, Blackstone EH, Grunkemeier GL, et al. Guidelines for reporting mortality and morbidity after cardiac valve interventions. Eur J Cardiothorac Surg. 2008;33: 523-8.

7. Gerosa G, Tarzia V, Rizzoli G, Bottio T. Small aortic annulus: the hydrodynamic performances of 5 commercially available tissue valves. J Thorac Cardiovasc Surg. 2006;131:1058-64.

8. Jamieson WRE, Forgie R, Hayden RI, Langlois Y, Ling H, Stanford EA, et al. Hemodynamic performance of Mitroflow aortic pericardial bioprosthesis-optimizing management for the small aortic annulus. J Thorac Cardiovasc Surg. 2010;58:69-75.

9. Mazzucottelli JP, Bertrand PC, Loisance DY. Durability of the Mitroflow pericardial valve at 1 year. Ann Thorac Surg. 1995;60(Suppl):S603-4.

10. Asch FM, Heimansohn D, Doyle D, Dembitsky W, Ferdinand FD, Swanson J, et al. Mitroflow Aortic Bioprosthesis 5-Year Follow-Up: North American prospective multicenter study. Ann Thorac Surg. 2012;94:1198-203.
11. Minami K, Zittermann A, Schulte-Eistrup S, Koertke H, Korfer R. Mitroflow synergy prostheses for aortic valve replacement: 19 years experience with 1516 patients. Ann Thorac Surg. 2005;80:1699-705.

12. Yankah CA, Pasic M, Musci M, Stein J, Detschades C, Siniawski H, et al. Aortic valve replacement with the Mitroflow pericardial bioprosthesis: durability results up to 21 years. J Thorac Cardiovasc Surg. 2008;136:688-96.

13. Banbury MK, Cosgrove DM III, White JA, Blackstone EH, Frater RW, Okies JE. Age and valve size effect on the long-term durability of the Carpentier-Edwards aortic pericardial bioprosthesis. Ann Thorac Surg. 2001:72:753-7.

14. Piccardo A, Blossier JD, Le Guyader A, Orsel I, Sekkal S, Cornu E, et al. Fate of aortic bioprostheses: a 18-years experience. J Thorac Cardiovasc Surg. 2016; 151:754-61.e1.

15. Senage T, Le Tourneau T, Foucher Y, Pattier S, Cueff C, Michel M, et al. Early structural deterioration of Mitroflow aortic bioprosthesis. Mode, incidence, and impact on outcome in a large cohort of patients. Circulation. 2014;130: 2012-20.

16. Pomar JL, Jamieson WR, Pelletier LC, Gerein AN, Castella M, Brownlee RT Mitroflow pericardial valve bioprosthesis: clinical performance to ten years Ann Thorac Surg. 1995;60(2 Suppl):S305-9.

17. Pomar JL, Jamieson WR, Pelletier LC, Castella M, Germann E, Brownlee RT Mitroflow pericardial bioprosthesis experience in aortic valve replacement $>$ or $=$ to 60 years of age. Ann Thorac Surg. 1998;66(6 Suppl):553-6.

18. Alvarez JR, Sierra J, Vega M, Adrio B, Martinez-Comendador J, Guide F, et al Early calcification of the aortic Mitroflow pericardial bioprosthesis in the elderly. Interact Cardiovasc Thorac Surg. 2009;9:842-6.

19. The ISTHMUS Investigators. The Italian study on the Mitroflow postoperative results (ISTHMUS): a 20-year, multicentre evaluation of Mitroflow pericardial bioprosthesis. Eur J Cardiothorac Surg. 2011;39:18-26.

Key Words: aortic valve, heart valve prosthesis, structural valve deterioration 


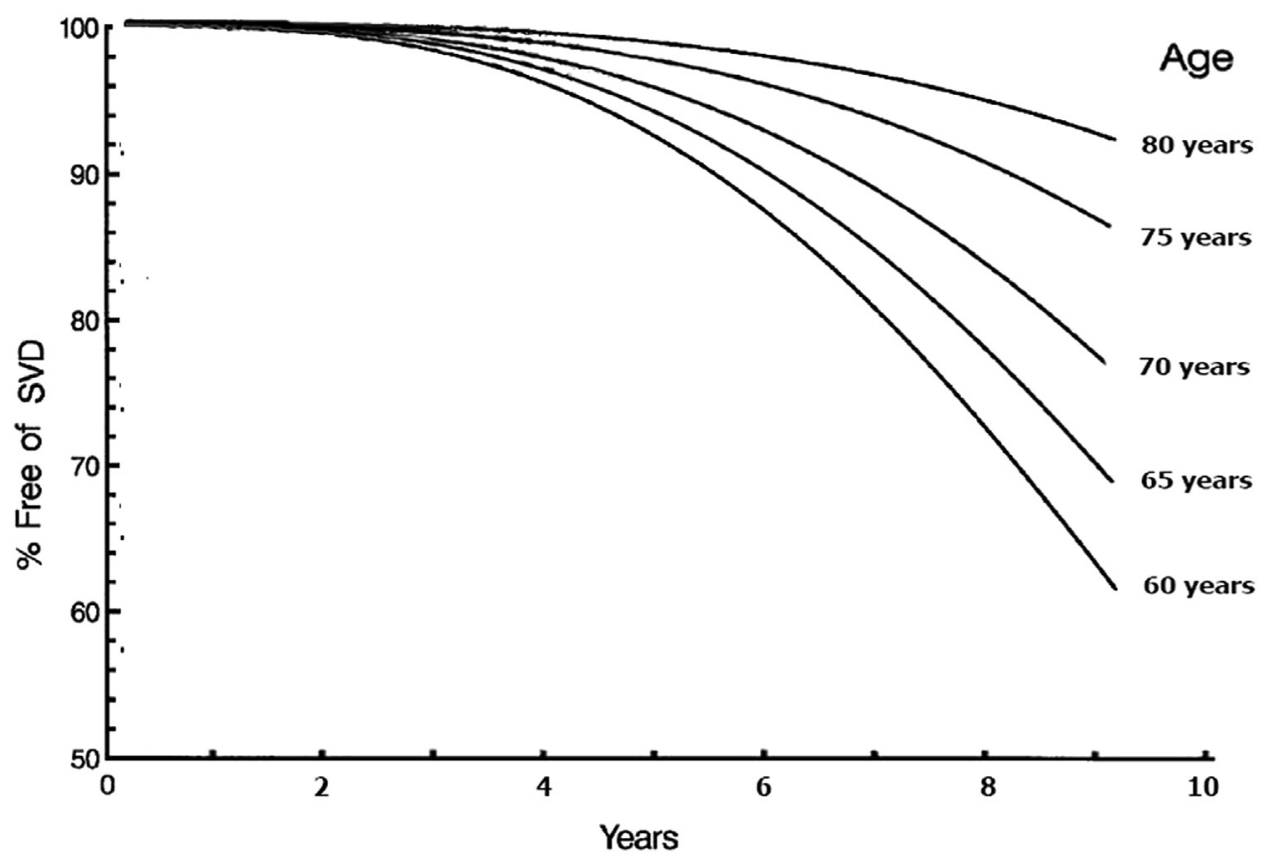

FIGURE E1. Nomogram of time from implant expected freedom from structural valve deterioration $(S V D)$ stratified by age-class. 
TABLE E1. Univariate and multivariate analysis of risk factors for overall mortality, cardiac and valve-related mortality, structural valve deterioration, and reoperation for structural valve deterioration

\begin{tabular}{|c|c|c|c|c|c|c|c|}
\hline \multirow[b]{2}{*}{ Univariable variable } & \multicolumn{3}{|c|}{ Overall mortality } & \multirow[b]{2}{*}{ Univariate variable } & \multicolumn{3}{|c|}{ Cardiac mortality } \\
\hline & ExpBeta & $P$ value & $\mathbf{9 5} \%$ Confidence interval & & ExpBeta & $P$ value & $\mathbf{9 5} \%$ Confidence interval \\
\hline Age & 1.08 & $<.0001$ & 1.04-1.12 & Age & 1.07 & .0228 & $1.00-1.13$ \\
\hline Sex & 0.66 & .1126 & $0.40-1.09$ & Sex & 0.35 & .0028 & $0.18-0.69$ \\
\hline Body surface area & 1.04 & .9541 & $0.25-4.26$ & Body surface area & 3.77 & .2215 & $0.45-31.31$ \\
\hline Body mass index & 0.99 & .8406 & 0.94-1.04 & Body mass index & 1.03 & .3681 & $0.96-1.11$ \\
\hline Ejection fraction & 0.96 & .0008 & 0.94-0.98 & Ejection fraction & 0.98 & .4806 & $0.95-1.02$ \\
\hline Dyslipidemia & 0.77 & .2574 & $0.49-1.20$ & Dyslipidemia & 0.88 & .7238 & $0.45-1.73$ \\
\hline Diabetes & 1.49 & .0808 & $0.95-2.33$ & Diabetes & 1.70 & .1311 & $0.85-3.38$ \\
\hline Hypertension & 0.78 & .2833 & $0.50-1.22$ & Hypertension & 0.58 & .1158 & $0.30-1.13$ \\
\hline Chronic renal failure & 2.20 & .0021 & $1.33-3.65$ & Chronic renal failure & 2.29 & .0379 & $1.05-5.00$ \\
\hline $\begin{array}{l}\text { Chronic obstructive } \\
\text { pulmonary disease }\end{array}$ & 1.32 & .3275 & $0.75-2.34$ & $\begin{array}{l}\text { Chronic obstructive } \\
\text { pulmonary disease }\end{array}$ & 1.68 & .2166 & $0.74-3.81$ \\
\hline Associated procedure & 1.61 & .0267 & $1.05-2.45$ & Associated procedure & 1.32 & .4023 & $0.69-2.52$ \\
\hline Valve size & 1.15 & .4862 & $0.76-1.74$ & Valve size & 0.83 & .5929 & $0.43-1.61$ \\
\hline Prosthesis-patient mismatch & 0.91 & .8774 & $0.29-2.86$ & Prosthesis-patient mismatch & 0.75 & .7828 & $0.10-5.45$ \\
\hline
\end{tabular}

\begin{tabular}{|c|c|c|c|c|c|c|c|}
\hline \multirow[b]{2}{*}{ Univariate analysis } & \multicolumn{3}{|c|}{ Valve-related mortality } & \multirow[b]{2}{*}{$\begin{array}{l}\text { Interval-censored } \\
\text { hazard function }\end{array}$} & \multicolumn{3}{|c|}{ Structural valve deterioration } \\
\hline & ExpBeta & $P$ value & $\begin{array}{l}95 \% \text { Confidence } \\
\text { interval }\end{array}$ & & ExpBeta & $P$ value & 95 $\%$ Confidence interval \\
\hline Age & 1.09 & .0154 & 1.01-1.16 & Age & 0.89 & .0301 & $0.81-0.98$ \\
\hline $\operatorname{Sex}$ & 0.35 & .0129 & $0.15-0.80$ & Sex & 1.12 & .9173 & $0.33-3.68$ \\
\hline Body surface area & 5.81 & .1721 & $0.47-71.94$ & Body surface area & 0.50 & .6842 & $0.02-10.41$ \\
\hline Body mass index & 1.02 & .5464 & $0.94-1.12$ & Body mass index & 0.99 & .9823 & $0.91-1.11$ \\
\hline Ejection reaction & 1.01 & .5954 & $0.96-1.06$ & Ejection fraction & 1.07 & .0373 & $1.01-1.13$ \\
\hline Dyslipidemia & 0.72 & .4484 & $0.31-1.65$ & Dyslipidemia & 0.71 & .4298 & $0.29-1.69$ \\
\hline Diabetes & 1.29 & .5558 & $0.54-3.08$ & Diabetes & 1.88 & .1698 & $0.77-4.58$ \\
\hline Hypertension & 0.15 & .564 & $0.25-1.23$ & Hypertension & 0.69 & .4522 & $0.30-1.77$ \\
\hline Chronic renal failure & 1.51 & .4436 & $0.52-4.38$ & Chronic renal failure & 0.37 & .2703 & $0.05-2.84$ \\
\hline $\begin{array}{l}\text { Chronic obstructive } \\
\text { pulmonary disease }\end{array}$ & 0.95 & .9399 & $0.28-3.16$ & $\begin{array}{l}\text { Chronic obstructive } \\
\text { pulmonary disease }\end{array}$ & 1.12 & .8002 & $0.29-3.89$ \\
\hline Associated procedure & 1.61 & .2342 & $0.73-3.54$ & Associated procedure & 1.40 & .7732 & $0.63-3.35$ \\
\hline Valve size & 0.84 & .6768 & $0.38-1.85$ & Valve size & 0.98 & .8873 & $0.45-2.73$ \\
\hline Prosthesis-patient mismatch & 0 & .9874 & $1.6 \mathrm{E}-173-5.8 \mathrm{E}+162$ & Prosthesis-patient mismatch & 0.92 & .9556 & $0.19-6.98$ \\
\hline
\end{tabular}

\begin{tabular}{|c|c|c|c|c|c|c|c|}
\hline \multirow[b]{2}{*}{ Univariate analysis } & \multicolumn{3}{|c|}{ Reoperation for structural valve deterioration } & \multirow[b]{2}{*}{ Multivariable analysis } & \multicolumn{3}{|c|}{ Overall mortality } \\
\hline & ExpBeta & $P$ value & 95\% Confidence interval & & ExpBeta & $P$ value & $\mathbf{9 5} \%$ Confidence interval \\
\hline Age & 0.85 & .0166 & $0.75-0.97$ & Age & 1.08 & .0001 & 1.03-1.12 \\
\hline Sex & 1.48 & .7079 & $0.18-11.63$ & Sex & NA & NA & NA \\
\hline Body surface area & 0.04 & .2261 & $0.00-6.40$ & Ejection fraction & 0.97 & .0154 & 0.95-0.99 \\
\hline Body mass index & 0.92 & .3413 & $0.78-1.08$ & Chronic renal failure & 1.34 & .2931 & $0.77-2.33$ \\
\hline Ejection fraction & 0.04 & 1.0929 & $1.00-1.19$ & Associated procedure & 1.52 & .0565 & $0.99-2.33$ \\
\hline Dyslipidemia & 1.52 & .5093 & $0.44-5.25$ & & & & \\
\hline Diabetes & 2.46 & .1637 & $0.69-8.70$ & & & & \\
\hline Hypertension & 1.23 & .7861 & $0.26-5.80$ & Age & 1.08 & $<.0001$ & 1.04-1.12 \\
\hline Chronic renal failure & 0 & .9501 & $2.7 \mathrm{E}-163-276 \mathrm{E}+150$ & Ejection fraction & 0.96 & .0044 & $0.94-0.99$ \\
\hline $\begin{array}{l}\text { Chronic obstructive } \\
\text { pulmonary disease }\end{array}$ & 1.65 & .5263 & $0.35-7.76$ & Associated procedure & 1.56 & .0379 & $1.02-2.39$ \\
\hline Associated procedure & 1.53 & .5084 & $0.43-5.40$ & & & & \\
\hline Valve size & 1.53 & .5084 & $0.43-5.40$ & & & & \\
\hline Prosthesis-patient mismatch & 2.42 & .4044 & $0.30-19.26$ & & & & \\
\hline
\end{tabular}

\begin{tabular}{lcccccccc} 
& \multicolumn{3}{c}{ Valve-related mortality } & & \multicolumn{3}{c}{ Cardiac mortality } \\
\cline { 2 - 4 } \cline { 6 - 9 } Multivariable analysis & ExpBeta & $\boldsymbol{P}$ value & $\mathbf{9 5} \%$ Confidence interval & Multivariable analysis & ExpBeta & $\boldsymbol{P}$ value & $\mathbf{9 5} \%$ Confidence interval \\
\hline Age & $\mathbf{1 . 0 7}$ & $\mathbf{. 0 2 6 2}$ & $\mathbf{1 . 0 0 - 1 . 1 5}$ & Age & Sex & $\mathbf{1 . 0 6}$ & $\mathbf{. 0 3 8 5}$ & $\mathbf{1 . 0 0 - 1 . 1 2}$ \\
Sex & $\mathbf{0 . 3 8}$ & $\mathbf{. 0 2 3 8}$ & $\mathbf{0 . 1 7 - 0 . 8 7}$ & $\mathbf{0 . 3 7}$ & $\mathbf{. 0 0 5}$ & $\mathbf{0 . 1 9 - 0 . 7 4}$ \\
\hline
\end{tabular}

Bold indicates significant risk factors entering the multivariate analysis. $N A$, Not available. 